\title{
Post-Streptococcal Arthritis
}

National Cancer Institute

\section{Source}

National Cancer Institute. Post-Streptococcal Arthritis. NCI Thesaurus. Code C119025.

The occurrence of arthritis after infection with group A streptococcus. It is non-

migratory, protracted in course, and poorly responsive to anti-inflammatory agents.

(from Textbook of Pediatric Rheumatology, 6th ed. Cassidy, Petty, Laxer, and Lindsley) 